\title{
A Study of the Development and Promotion of Chinese Opera Movie in Rural Areas: An Investigation and Reflection on Hunan Rural Movie of Local Opera Project in China
}

\author{
Xiu-Feng Yang ${ }^{1} \&$ Wei Zheng ${ }^{2}$ \\ ${ }^{1}$ Department of Directing, National Academy of Chinese Theatre Arts, Beijing, China \\ ${ }^{2}$ School of Marxism Studies, Central University of Finance and Economics, Beijing, China \\ Correspondence: Wei Zheng, School of Marxism Studies, Central University of Finance and Economics, Beijing 100081, \\ China. E-mail: zhengw2020@126.com
}

Received: April 18, $2020 \quad$ Accepted: May 2, 2020 Online Published: May 11, 2020

doi:10.11114/ijecs.v3i1.4849

URL: https://doi.org/10.11114/ijecs.v3i1.4849

\begin{abstract}
Chinese opera movie is a special form of art developed from the combination of traditional Chinese opera and cinematographic art. In the inheritance and development model represented by "Hunan Rural Movie of Local Opera Project" (also called "Hunan Local Opera Movie Project") , Chinese public administrators, traditional opera artists and opera movie makers target rural areas, adhere to traditional opera culture, and explore new ways to develop and promote opera movie. They put effort into upholding orthodox opera and innovating for audience, conducting a beneficial practice of making traditional culture resonate by current rural audience again in way of producing and disseminating opera movies. Their practice has contributed to the creative development of opera movie in rural areas.
\end{abstract}

Keywords: traditional Chinese opera, opera movie, rural areas, observation

\section{Introduction}

Since entering the new century, opera movie has gradually moved from stillness to rejuvenation, then radiates vitality and shows signs of prosperity. Hundreds of excellent operas from over 30 types of Chinese opera, including Peking opera, Yu opera, Yue opera and Huangmei opera, have moved from stage to screen. While following the traditional movie model, some movies represented by Dream of a Lady's Chamber and Honest Official Yu Chenglong have new aesthetic inclinations in audio-visual expression and bring open information to stage plays with reconstructed lens language. Meanwhile, the involvement of new technologies like 3D and 4K have brought new changes and developments to the expressive form of operas and helped opera movie constantly update and transcend its aesthetic standards. The opposite to the prosperity of filmmaking is the decline of the audience that when we again talk about The Wild Boar Forest, The Butterfly Lovers, Tianxianpei, and even The Legend of White Snake which was sensationally viewed 700 million times in the 1980s, it is just like telling stories today. The "Hunan Rural Movie of Local Opera Project" was exactly launched under this atmosphere. Different from the resource allocation of "Peking Opera Movie Project" and the targeted production of "Plum Blossom Prize Digital Movie Project", it starts with deep traditional opera deposits in different places, then multiple types of opera are produced orderly, concerted efforts are made to promote them and form a clear bond between the work and the audience. Moreover, the inner strength and generation effect contained in it bring some references and thoughts to the development of opera movie at present.

\section{View}

Traditional Chinese opera is a gem of Chinese national art. Since the production of China's first movie Dingjun Mountain (based on Chinese Peking opera Dingjun Mountain), movie and opera have formed ties. As a development model for Chinese opera movie at present, "Hunan Rural Movie of Local Opera Project" was initiated in 2012. Its overall plan is to make typical types of opera and classic operas of Hunan local operas into movies in ten years and project them in tens of thousands of villages across the province, to give traditional Chinese opera the wings of movie to soar.

\section{1 "Hunan Rural Movie of Local Opera Project" Embodies the Inheritance and Observance of Chinese Opera Culture}

The specific objective of the "Hunan Rural Movie of Local Opera Project" is to produce ten opera movies and project 600,000 times in the province. This measure quantifies opera movies in the scope and number of projection. Its core 
impetus is from cultural confidence in the development of traditional Chinese opera, personal experience of significant effects generated by the spreading traditional operas with the help of movie, and more importantly the confidence and impetus brought by an understanding of public cultural needs by going deep into the grassroots.

Hunan, the birthplace of Xiang-Chu culture, has a long history of local opera culture. After experiencing Chu ballad in the Han dynasty, the prevalence of puppet show in the Tang dynasty, profoundly influenced by Yuan zaju opera and Yiyang Qiang, and devotedly absorbing and developing at different times, all types of opera are gradually perfected in terms of tune system, music style, technique of expression and other aspects. Numerous troupes perform frequently, and have created a great number of classic traditional operas, including The Story of Pipa, Meng Lijun, Fan Lihua, Li Sanniang and Lotus Lantern, forming a stable audience. Up to now 19 types of opera, including Hunan opera, Qi opera, Hanchu opera, flower-drum opera, Wuling opera, Baling opera, Huadeng opera, Miao opera and Dong opera, remain full of life and unswervingly pass down in the jungle of culture, producing a batch of new masterpieces and offering opera movie making lots of texts to choose from.

Hunan operas are seen at several important stages of the development of opera movie, and the most influential one is flower-drum opera Ring A Gong and Tinker A Pan in 1965. With unique local expression, this opera narrates the collision between emotion and reason. Lan Ying, a brisk, clever, saucy girl who pursues love boldly, played by Li Guyi, has left a beautiful and deep impression on people. "Wild chrysanthemums blossom, blossom. Wind blows river glittering, glittering. Graduation song was sung together last year, work after returning home with a good rapport. I work, he tinkers a pan, he tinkers a pan." Daily and interesting languages make the audience and the performance closer to each other, allows the audience to acquire great artistic pleasure while immersed in an empathic ambience, favored by people across the country. Besides, it greatly promoted the development of opera types and deserves to be called a grand occasion in the history of Hunan opera. Before that, Hunan opera Praying to the Moon(1957) was the first time for Hunan opera to enter screen, showing special and distinct artistic qualities in way of storytelling, performance, diction, voice, music and other aspects. After 1978, Hunan opera Malingdao entered screen, telling a series of mishaps and conflicts between Pang Juan and Sun Bin, namely "send letter-pare kneecap — burn bamboo slips - feign madness", and narrating the stories of eminent people in the pre-Qin period of China and allegorical traditional cultural characters. The characters are real and vivid in the storyline; musical images and characters form synergy and accurately shape the personality traits of Pang Juan and Sun Bin; in the movie, a number of opera skills like turning over and rolling are presented from multiple angles, perfectly embodying the state of mind of the characters then. Moreover, the movie delicately and artistically records and displays the consummate technique of performers. Even now, these works have made an effective contribution to spreading and popularizing Hunan local operas, which not only expands the scope of transmission of different types of opera but also increases the intensity of transmission in their place.

After rural movie projection began to constantly roll out in all provinces, cities and regions since 1998, Hunan province built 1,727 mobile projection teams in the following five years, serving 54,000 villages. Ranging from feature film, documentary, cartoon to art movie and commercial movie, all movie genres compete on the same arena, which reminds people of the pleasant experience and cultural need of watching opera movie in their memory. "I chatted with projectionists, who told me that rural people don't necessarily like those blockbusters projected in cities, because rural areas still enjoy theatergoing, but we have not filmed Hunan local operas for decades, so they have nothing to project. We even invited a consulting firm to do a survey by questionnaire. After the survey, we determined to launch Hunan Local Opera Movie Project." said the person in charge of the Hunan Charity Film Media Center. It follows that the prime impetus to the "local opera movie project" is from the birthplace which nurtures operas and makes it thrive and the tremendous interest in traditional opera of people in this land. Furthermore, this power has brought positive impetus to filmmaking and become the start key from "sporadic presence" to "collective presence".

\section{2 "Hunan Rural Movie of Local Opera Project" Embodies the Creation Orientation of Adhering to Orthodox and Seeking Innovations}

Initiating opera movie and making it a warm medium between the stage and the audience and making it novel with lingering charm need both passion and composure, persistence and tenacity. We see that the "Hunan Local Opera Movie Project" has gone through eight years and completed the mission of producing eight movies, namely Five Daughters Offering Felicitation (flower-drum opera, 2012),Cousin's Anecdotes(flower-drum opera, 2013), Li Sanniang (Qi opera, 2014), Sons and Daughters (flower-drum opera, 2015), Wang Hua Buying the Father (Hanju opera, 2015), Meng Jiangnv (Hanju opera, 2016), Zhao Zilong Takes Guiyang by Tactics (Hunan opera, 2017), Li Zhen Returning Home (Hunan opera, 2018) and The Underworld (Baling opera, 2019), which won numerous awards and honors successively and made fruitful efforts in distribution and projection.

\subsubsection{Lightness and Dedication Guarantees the Progress of Filmmaking}

In terms of the selection of operas, there are traditional opera, modern opera and new historical opera; as for the types of 
opera, there are widely known types, such as Hunan opera and flower-drum opera and Qi opera which has strong local characteristics. The selection criteria need to take the artistic standards of the opera itself as well as the aesthetic needs of the audience into consideration, to delight farmers. The commercial return on filming an opera movie is low, so it is normally led by governmental cultural departments and given some financial support coupled with self-financing, with limited filming budget and strict cost control. Oftentimes, it cannot make ends meet. The selection criteria stick to artistic standards and public needs and rise above interests. In this way, many movies proudly walk towards the audience. These movies form a cultural name card printed with the spiritual connotations and demeanor of Hunan, with a unique form of value. Meanwhile, these works have conducted an earnest exploration to "comprehensively revitalize Hunan opera, flower-drum opera, Qi opera, Changde Han opera, Baling opera and other local operas and drive the creative breakthrough of Peking opera, Hunan Kunqu opera, leather silhouette show, Western opera, dance drama and other types of opera". To some degree, the communication medium of movie drives the creative transformation and innovative development of stage operas.

\subsubsection{Create the Cinematic Style of "One Opera, One Style"}

Since opera movie is the combination of the two forms of art, it not only follows the format of stage performance but also always instinctively seeks the possibilities of audio-visual performance. When virtuality and reality are integrated, it advances after all amid their competition for dominancy. Chinese opera is good at expressing emotions that the audience feel "emotions" and taste "reason" in intone with acting means upholding "less is more"; while movie chooses to be real, with narrative as the main axle when expressing "emotion" and "reason", and retains exquisite stage performance and presents a narrative more real than stage via field switch, camera movement, frame structure and time-space reorganization and other techniques. Expressing emotions, reason and stories is not only a fundamental task but also a core issue, and different ways of processing are manifested as different cinematic styles. In light of the works produced by the "Local Opera Project", currently six of nine works completed were produced by director Zhu Zhaowei and his team, and a stable team formed the foundation for tacit cooperation. They "adhere to" the quintessence of stage orthodox, "seek" the innovations of audio-visual expression, and strive to create the cinematic style of "one opera, one style".

Hunan opera Li Zhen Returning Home, as a historical opera, chooses typical scenes that can restore history on screen: a revolutionist goes from ignorance and confusion to the path of revolution amid the contrast between the flames of war and the real environment of peace, joyfulness and affection, offering crucial support to the improvement of the understanding of the emotions and thoughts of the characters. Meanwhile, movie's advantage in narrating is made full use of narrative structure is adjusted, and reality and past are combined more closely with a stronger sense of rhythm. At the end of the opera, in the brilliant and core aria "Sister Zhen Returning Home", Li Zhen affectionately sings out a deep understanding after from the masses and to the masses: "people are the most kind-hearted despite fierce storm". This touching feeling is the success of cinematic narration. As a traditional opera, Li Sanniang (Qi opera) gives an accurate description of the bitterness and fortitude of Li Sanniang who "carries water all day and grinds the mill at night till dawn" when waiting for the reunion with her husband and son. Moreover, the setting of key scenes like well and mill stresses a sense of reality and presents the ultimate beauty of poetic imagery, which deepens the emotional vein of things. Pavilion, millstone and quadrilateral curtain form a perspective line of landscape; in terms of texture, heaviness contrasts with gracefulness, offering multiple possible combinations of virtuality and reality. In the well scene, the mother and the son who do not know each other meet in heavy snow, surrounded by bare trees and withered grass shrouded in snow, the cruelty of reality is imprinted in this romantic ambience. Hanju opera Meng Jiangnv artistically records the special skill of Hanju opera, namely seeing with one eye. A performer keeps one eye unmoved and lets the other one rotates agilely, showing the insanity of the character. This is an applause-eliciting exclusive technique in theater. In the movie, for how to present this skill, especially in the face of the current audience, and arouse the connection between performance and emotions, instead of simply recording, the movie has put much effort into frames, to enable the audience to effortlessly accept the ingenuity of this skill when watching it.

In addition, other works also stick to the need to combine types and contents of opera to choose the most appropriate expression. For examples, collective performance of carrying sedan-chair without props in Wang Hua Buying the Father; Cousin's Anecdotes has full-bodied comedic style, constructed familiar yet unique characters, and preserved the strong flavor of flower-drum opera; in Five Daughters Offering Felicitation, the scene of offering birthday felicitations has a strong sense of reality and underlines the depiction of the expressions and mentality of its characters...In a manner of speaking, these opera movies do not only have unique implications, but also are the recreations on the premise of the respect for traditional Chinese opera, declaring the vigorous vitality of local art.

\subsubsection{Projection in Multiple Ways Increases the Reach of Transmission}

After years of producing, the artists become deeply aware that "promoting is the best way of inheriting. Traditional operas are often performed in theaters. In view of limited time and energy of performers, it is not easy for an opera to be 
performed for a hundred times in a year; besides, due to a variety of forms of art such as stage play, child play, acrobatics and dance drama and the consequent preferences, ticket price, transportation and theatre service among other multifaceted factors, there are only a few who go to the theater. Related data from the Ministry of Culture and Tourism show: in 2018, China has 2,478 venues for artistic performance and has held 178,900 art shows, lower by 15.5\% than last year; the art shows were viewed 58.62 million times, down by $8.2 \%$ than last year. In the face of prosperous cultural market, making traditional Chinese opera flow among the masses becomes a component of cultural diversity, and channels of communication are expanded to make more people watch the opera via more means, making it possible for the opera to be known and liked and for the audience to change from "be taken to the opera" to "take the initiative". Opera movie is one of the approaches to promote the art of Chinese opera, trailers and highlights edited from movies and a series of derivative videos like interviews are spread via diverse channels, including WeChat Official Account, Moment and network platforms, thus guiding and developing more professional opera fans in this process.

We should see that the "Hunan Local Opera Movie Project" makes full use of the resource advantage of the National Rural Charity Movie Projection Project, integrates motion picture projection and filmmaking under the guidelines of "business operation, market operation, government purchase, public benefit", and issues nearly 500,000 movies via the subscription platforms of the China Film New Countryside and the National Digital Program Center. 15 city, county and village cinema chains and 120 county (district and city) and village movie projection service stations were used to project these movie, ensuring the movies are projected "from mountaintop to sidehill" in villages and "enter squares, schools, communities and villages" in cities. The opera movie panorama month named "Opera Movies in Hunan" was conducted in the province, and tens of millions of people watched these movies, which started a craze for opera movie in Hunan and received good social response at one time.

\subsection{The "Hunan Rural Movie of Local Opera Project" Demonstrates Taking Root in the Audience is the Way of Long-term Development}

By straightening out the "Hunan Rural Movie of Local Opera Project", we should say that this series do not go after "peculiarity" nor "interests", displaying simple and placid creation. Besides, one can feel that the affection and mission of "born and raised here" is its ground, and concerted efforts of multiple types of operas publicized local traditional culture and improved cultural connotations of cities. Reflecting on its unique origin of force presented in production, issuance and projection and the resultant propagation effect can bring the current and future opera movie making some new thoughts and inspirations.

\subsubsection{Explore New Projection Paths to Meet the Needs of Target Audience and Boost Cultural Vitality}

Opera movie, as a movie genre, also follows the operating model of the movie industry in industrial process, but in fact, the distance between theatergoing consumers and opera leads to the absence of economic attribute. The seeming discordance between "what to see" and "who is seeing" is actually discrepancy between the audience and the content. In this case, in the era of "contend-dominated and audience-oriented" movie at present, we must answer the question: where is the audience of opera movie?

When the rural movie projection project is promoted at a higher national level and the path between movie and village is paved, when "the seer" and "the seen" begin to talk to each other, the target audience of opera movie start to show themselves, which finds one of the solutions to the long-standing problem facing opera movie, namely how to develop and expand the audience. This path is more suitable for the projection of opera movie than commercial cinema chain for two reasons: first, the main audience for cinemas is mostly young people, yet currently what opera movies present are not among the list of entertainment consumption; second, different from the habits of movie appreciation, Chinese opera is about "growing fond of it because of familiarity". It means the more you go to the opera, the more you are familiar with it, and the more you are familiar with it, the more you like it. It means opera movie is suitable to be watched repeatedly, which is unrealizable in cinemas. These two problems can be solved successfully by projecting movies in rural areas, because now the middle-aged and elderly and children are the majority in rural areas, who have a need for a cultural life of watching Chinese opera; what is more, the projection can achieve limited projection and is low-cost. Meanwhile, local opera is closely connected with local folk culture, and it has a relatively stable area of transmission and target audience from various reasons such as language, behavior and temperament. Furthermore, this propagation characteristic is still kept when an opera is made into a movie, and local cultural authorities and artists have a compelling obligation to create this kind of movie and have bright prospects in this area.

\subsubsection{Tradition and Time Cause a "Wormhole" Effect and Retain Native Accent and Nostalgia}

Traditional Chinese opera came from among the folks and grows among them. It coheres folk customs and local accents in this land, tells the stories of folks here, and demonstrates cultural details and inner cultural spirit contained in this land, with a unique form of value. With the advancement of the times and as rapid urbanization has changed the environment of this land, many young people move from villages to cities with a beautiful longing and ideal, while opera, which once 
played an important role in the cultural life of people, gradually lags behind the rapidly-changing trends of the times. When looking back again, the theatre sighingly sags. While private troupes which take root among the folks remain active in serving the grass-roots in different places, and high-quality operas still enjoy a large audience, which testifies to vigorous vitality that Chinese opera has kept. In terms of content, the texts of opera movies can still resonate among people of today. From the perspective of the audience: when life is more and more affluent and happiness index is increasingly high, hometown remains the most unforgettable deep at the heart, as it permeates the details of the life of everyone and haunts. In the precious memories of older people in China, watching the movie or opera in open air, listening to the humming of their neighbor or family, and etiquettes and customs in everyday interpersonal communication cause the "wormhole" effect when the white screen lights up, bringing the audience a time travel and to their memories, as it observes the mind and life of today and nurtures the heart of people.

Meanwhile, we must see that as urban landscape and cultural homogenization are intensified today, the contents and expressions of local opera are highly recognizable, operas are delivered to folks through movies, more memories and nostalgia are kept, and a beautiful spiritual homeland is created with great prospects.

\subsubsection{Screen and Stage Integrate and Coexist, Creating a New Situation of Mutual Reference}

Theoretically speaking, screen and stage will naturally form a circle of symbiosis since they produce the same content. The movie The Piano in A Factory released in 2011 was made into a stage play in 2012, adapted for a musical in 2013, and filmed as a 36-episode TV series in 2014; the stage play The Breakup Guru and Devil and Angel, the stage play Mr. Donkey and the musical Office entered screen; in 2009, NTlive (National Theatre Live) Project translated theatrical art into opera movie and spread them on a larger scale in the most economical and convenient way...These cross-media production and transmission are recognized by the market, and the audience is very likely to develop an interest in other forms of presentation because they have seen one. As for opera movie, its relationship with opera stage as mutual reference was formed as early as movie consciously chose Chinese opera as text when it entered China. The aria "Big Snow" added in Peking opera movie The Wild Boar Forest has become a classic aria in future stage, while Huangmei opera movie Tianxianpei only keeps $60 \%$ of libretto, which sets an example for and inspires the refinement of future stage performance. So, they help each other to succeed in the conversion from opera stage to screen.

On the other hand, the filmmaking process offers troupes and performers effective experience, and unordered filming poses some challenges to performers on traditional art stage, so grasping the consistency of inner emotions and external behaviors of a character will be a great challenge undoubtedly. "The filmmaking process helps me further cognize $\mathrm{Li}$ Zhen's ideological changes and behavioral clues and go much deeper into the heart of the character, which is a boost to my stage performance", said Wang Yangjuan, the actresses who played Li Zhen, after the movie was filmed. In addition, performance, costumes, makeup, props and other aspects are also coordinated amid running-in and control. And the filmmaking process offers performers unusual feelings and rewards in performance techniques, artistic accomplishment and other aspects, constructing a virtuous circle of self-improvement and self-enhancement.

\section{Conclusions}

When the importance of traditional Chinese culture is increasingly clearly cognized and receives serious attention, opera movie making, transmission practice and their meaning are self-evident. Then, we should think about how to find and expand the market and let the audience "walk in" and how to make the work and its feedback "down-to-earth", in order to spread the beauty of traditional Chinese opera better.

The "Hunan Local Opera of Movie Project" has conducted fruitful explorations in these dimensions. Stationed in Hunan, this project incessantly create based on local operas, records and keeps local excellent stage operas in a creative way and satisfies people's spiritual and cultural need to "go to the opera"; on the other hand, it has conducted a pioneering and practical exploration on letting traditional Chinese opera take root in the masses, accelerating the artistic dissemination and influence of local operas in Hunan to some degree. On a higher level, it is carried out not only for the audience, but also for allowing national opera to have successors and follow-up techniques and skills. Objectively speaking, it explored new approaches in terms of form, function and connotation, and its highlights are "mass production", "identifying target audience" and "promoting local cultural development".

In effect, when there is no longer any resistance to filming and watching, what opera movie faces are problems that are more fundamental and urgent: how to make the opera understandable to the audience, how to expand the target audience and narrow the distance between them, how to display diverse images and brilliant works, and how to retain elaborate production for current and future audience. These problems still need more explorations, and promoting Chinese opera movies in rural areas may be a beneficial attempt and practice at present. 


\section{References}

2018 Statistical Communique of Cultural and Tourism Development of the Ministry of Culture and Tourism of the People's Republic of China, 2019-05-30.

Gao, X. J. (2015). The Art of Movie, Beijing: China Film Press.

Hunan Provincial Department of Culture. (2015). Hunan 2015-2020 Stage Art Making Plan.

Zhu, Z. W. (2019). Practice and Thought on the Filmmaking of Opera Film Directors.

\section{Copyrights}

Copyright for this article is retained by the author(s), with first publication rights granted to the journal.

This is an open-access article distributed under the terms and conditions of the Creative Commons Attribution license (http://creativecommons.org/licenses/by/4.0/). 